\title{
Domestic Accidents among the Children in a Selected Rural Area
}

\author{
Asma $\mathrm{MNF}^{1}$, Yesmin $\mathrm{F}^{2}$, Haque $\mathrm{M}^{3}$
}

Conflict of Interest: None

Received: 17.05 .2020

Accepted: 15.09 .2020

www.banglajol.info/index.php/JSSMC
Key Words:

Domestic accidents, Rural area children.

\begin{abstract}
Background: Children are very prone to accidents which more often occur in and around the house. These domestic accidents are one of the five leading causes of death in both industrialized and developing countries.
\end{abstract}

Objectives: The present study was conducted to determine the proportion and pattern of domestic accidents among the under 15 children of rural areas of Bangladesh.

Methodology: This cross-sectional type of descriptive study was carried out from October 2015
to May 2016. Parents of 735 children below 15 years of age from Kaliakair Upazilla under the
district of Gazipur were interviewed through a pretested semi structured questionnaire. The
study place was selected conveniently and the sampling technique was purposive type of non-
probability sampling.

Results: The present study revealed that, about one fourth (23.4\%) of the 735 children were affected by domestic accidents. Among them injuries from sharp objects and falls from heights were equal (33.1\% each) and were the leading causes of domestic accidents. The next leading cause was due to burns (8.7\%) and then burns from hot liquids were $7.6 \%$, Injuries from blunt objects were $6.4 \%$ and drowning were $4.1 \%$. Kerosene poisoning $(0.6 \%)$, insect bites $(0.6 \%)$ and snakebites (0.6\%) had the lowest incidence. Majority (53.7\%) of the children in this study were male and $46.3 \%$ were female and their mean age was $7.05( \pm 3.842)$ years. Mean age of the affected children was 7.66 ( \pm 3.583$)$ years and age group of 7-9 years were largely $(29.1 \%)$ affected.Male children were affected more (59.3\%) than female children.The children of class I$V$ were affected mostly (48.8\%). Most of the children of the study as well as the affected children belonged to nuclear families $(61.8 \% \& 65.7 \%$ respectively). The mean monthly family income of the respondents was 17260.82 ( \pm 12726.70$)$ taka and that of the affected group was 17125( \pm 13303.60$)$ taka. Children living in semi pucca house affected by domestic accidents more (65.1\%) than children living in other housing. Most (56.4\%) of the accidents occurred in the surroundings of the house and the rest (43.6\%) occurred inside the house. Maximum (32.55\%) accidents took place in winter, whereas $30.23 \%$ in summer, $23.25 \%$ in the rainy season, $6.4 \%$ in autumn, $6.4 \%$ in late autumn, \& $1.17 \%$ in spring. All the 7 cases of drowning occurred in rainy season. It was found that only $6.98 \%$ of affected children suffered from disabilities. Among the affected children $59.8 \%$ took treatment and $7 \%$ children took preventive measures.

Conclusion: From this study it was concluded that nearly a quarter of the children were affected by domestic accidents and the leading causes of the accidents were injuries from sharp objects and falls from heights. To build up awareness and explore the situation in detail, in depth community based epidemiological study may be carried out by covering whole population.

[J Shaheed Suhrawardy Med Coll 2020; 12(2): 100-108] DOI: https://doi.org/10.3329/jssmc.v12i2.56891
1. Dr. M. N. Fahmida Asma, Associate Professor, Department of Community Medicine, Shaheed Suhrawardy Medical Collage

2. Dr. Fouzia Yesmin, Associate Professor, Department of Community Medicine, Shaheed Suhrawardy Medical College

3. Prof. (Dr) Musarrat Haque, Professor, Community Medicine Correspondence to: Dr. M. N. Fahmida Asma, Associate Professor, Department of Community Medicine, Shaheed Suhrawardy Medical Collage. Mobile No.: 01720318398, E-mail: fahmida_asma@yahoo.com

\section{Introduction and Background Information}

An accident is an undesirable, incidental and unplanned event occurring in a particular time and place with marked consequences, that could have been prevented had circumstances leading up to the accident been recognized, and acted upon, prior to its occurrence. 
Accidents represent a major epidemic of noncommunicable disease in the present century. Accidents can be classified into: Road traffic accidents, Domestic accidents, Industrial accidents, Sports accidents, Accidents in public places. ${ }^{1}$

Accident implies a generally negative outcome of varying measures, including distress to the victim and their family due to disability or loss of productivity. These effects are detrimental to both the individual and the society. ${ }^{1}$

Road traffic accident (RTA) occurs when a vehicle collides with another vehicle, pedestrian, animals, road debris, or other stationary obstruction i.e. a tree or utility pole. ${ }^{1}$ In many countries, motor vehicle accidents rank first among all fatal accidents. Every year almost 1.3 million people die from road accidents in the world. In addition, for every death, there are as many as 20-50 serious injuries and 1020 serious injuries requiring long periods of extensive care, nursing and treatment. ${ }^{2}$

Domestic accident is an accident that takes place at home or in its immediate surroundings or more generally, all accidents not connected with traffic, vehicles, sport and industry. Most common types include burning, drowning, fall from height, chocking, cuts, poisoning, electrocution, insect or animal bites etc. ${ }^{2}$ Domestic accidents are one of the five leading causes of death in industrialized and developing countries. ${ }^{3}$

In $1974,18,335$ people died from accidents in the UK equivalent to the population of a reasonably sized town. Every year over 1 million children under the age of 15 years of experience an accident in or around the home. ${ }^{4}$

The problem of childhood domestic accident is more severe in the developing countries like ours, due to overcrowding and lack of consciousness and facilities. Rural areas, shanty towns and informal dwellings are the places most prone to accidents. In Bangladesh, the most common household accidents are drowning, fall from height, burning, chocking, cuts, poisoning, electrocution etc. The most significant amount of injuries occur due to fall; these constitute about $1 / 3^{\text {rd }}$ of all household injuries. Fatality is very high among infants due to associated brain injury. ${ }^{3}$

A noticeable number of deaths and injuries occur from drowning or near drowning. According to the UNICEF, in Bangladesh there were 946 officially reported flood related deaths since mid-August, 2007 with drowning accounting for 816 of them. Over $86 \%$ of all the deaths were due to drowning, and over $90 \%$ of these cases were children, mostly under five. According to the BHIS, nearly 17,000 children drown annually in Bangladesh, an average of about 46 each day. At the same time, about four times this number nearly drowns, the number of reported cases being 68,000 a year. $^{5}$

Burn rate among females is higher than in male, and most cases are accidental. Overall mortality rate due to burn is
2.2 per 1,00,000 population per year. Most occurrences were observed in the rural areas; $90 \%$ take place at home. ${ }^{6}$

A common cause of disability and death in Bangladesh is electrocution. The average rate of nonfatal childhood electrocution was 53.2 per 1,00,000 population per year. The rate was found to be significantly higher among male children compared to that among females, which were 66.7 and 39.2 per 1,00,000 population per year respectively. The rate was found to be higher in rural areas than the

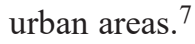

Other important causes of damage and injuries include cuts, chocking, poisoning etc. The overpopulation of our country, overcrowding of families, improper housing and lack of consciousness, proper education and adequate training can be stated as their major causes. This research addresses the nature and circumstances of domestic accidents, the presence or absence of permanent disability and the measures taken to prevent them. ${ }^{3}$

\section{Methodology}

This cross sectional type of descriptive study was conducted at Kaliakair Upazilla in the district of Gazipur. The study was conducted at 3 unions namely Shrifoltoli, Baliadi and Atabaha. The unions were selected conveniently. Respondents were selected purposively.

Children below 15 years of age were the study population. Respondents were the parents of the children below 15 years of age of Kaliakair Upazilla who respond to the questionnaire. The study was carried out from October 2015 to May 2016. Sample size was calculated by using the formula from "A Practical Manual of Sample Size Determination in Health Statistics" by S.K.L wanga and S. Lemeshow, WHO. Though the calculated sample size was 384, within the data collection period parents of 735 children below 15 years of age were interviewed. Data were collected by face to face interview through an interviewer administered pretested semi-structured questionnaire with the respondents.At the end of the day of data collection, each questionnaire was checked to see whether the questionnaire was filled completely and consistently. Then data were analyzedin computer with SPSS-16 version programme.

\section{Results}

The present study revealed that 172 (23.4\%) of 735 childrenhad experienced domestic accidents in previous one year and 563 (76.65\%) had not (Fig.-1).

Ages of the children of this study were from 1 year to 15 years. Mean age of the children was $7.05( \pm 3.842)$ years. Out of 735 children, $27.9 \%$ children were between the age group of 4-6 years, $22.2 \%$ of the children were between the age group of 7-9 years. On the other hand, only $11.3 \%$ of the children were between the ages of $13-$ 
15 years. The data showed that out of 735 children, $53.7 \%$ were male and $46.3 \%$ were female while majority $(81.6 \%)$ were Muslims, $18.2 \%$ were Hindus and $0.1 \%$ was Christians.

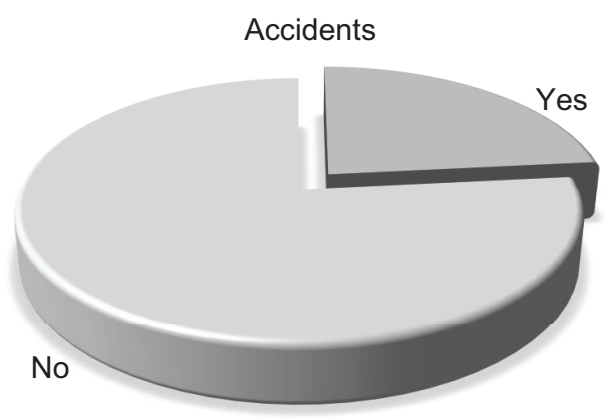

Fig.-1: Distribution of the children by occurrence of domestic accidents in last one year

The study showed that $64(8.7 \%)$ of children's father were illiterate \& rest 671 (91.3\%) were literate having different levels of education. Among the literates, $9.1 \%$ could only write their names. Out of 735 children's mothers, 79 (10.7\%) were illiterate \& rest $656(89.3 \%)$ were literate having different levels of education. Among the literates, $9.7 \%$ could only write their names. Most of the children's fathers, i.e. 365 (49.7\%) were businessmen. Rest of the fathers were service holders (21.2\%), farmers $(12.0 \%)$ or in other professions $(17.1 \%)$ while most of the children's mothers, i.e. 657 (89.4\%) were housewives. Rest of the mothers were service holders $(6.7 \%)$, business women $(1.1 \%)$ or in other professions (2.9\%).

The study revealed that most (61.8\%) of the 735 children, belonged to nuclear families and rest $(38.2 \%)$ belonged to joint family. The family members of the respondents of this study ranged from 3 to 25 in number. The mean number of family members was $5.66( \pm 2.87)$. Among 735 respondents, $65.4 \%$ had 5 or less family members. Monthly family income ranged from Tk. 1,000 to Tk. 1,00,000 and the mean income was Tk. $17260.82( \pm 12726.70)$.

Regarding housing, $21.1 \%$ of 735 children dwelt in kacha house, $61.1 \%$ in semi pucca house and $17.8 \%$ in pucca house.

Among the 735 children $90.2 \%$ used to drink water from tube well, $1 \%$ from well and $8.8 \%$ from other sources, i.e. motor pumps and $86.5 \%$ used sanitary latrine and $13.5 \%$ used non-sanitary latrine (Table-I).

\section{Table I}

Socio-demographic characteristics of the children

Socio-demographic Affected Not affected Total Characteristics children children Children Frequency Frequency Frequency

(\%) (\%)

(\%)

Total 172(100\%) $563(100 \%) 735(100 \%)$

Age

$\begin{array}{lccc}\text { 1-3 years } & 26(15.1) & 129(22.9) & 155(21.1) \\ \text { 4-6 years } & 41(23.8) & 164(29.1) & 205(27.9) \\ \text { 7-9 years } & 50(29.1) & 113(20.1) & 163(22.2) \\ \text { 10-12 years } & 34(19.8) & 95(16.9) & 129(17.6) \\ \text { 13-15 years } & 21(12.2) & 62(11.0) & 83(11.3) \\ \text { Gender } & & & \\ \text { Male } & 102(59.3) & 293(52.0) & 395(53.7) \\ \text { Female } & 70(40.7) & 270(48.0) & 340(46.3) \\ \text { Religion } & & & \\ \text { Islam } & 130(75.6) & 470(83.5) & 600(81.6) \\ \text { Hinduism } & 41(23.8) & 93(16.5) & 134(18.2) \\ \text { Christianity } & 1(0.6) & 0(0.0) & 1(0.1)\end{array}$

Level of education

$40(23.3) \quad 176(31.2) \quad 216(29.4)$

Can sign only $\quad 9(5.2) \quad 40(7.1) \quad 49(6.7)$

$\begin{array}{llll}\text { Class I-V } & \text { 84(48.8) } & \text { 225(40) } & \text { 309(42) }\end{array}$

$\begin{array}{llll}\text { Class VI-X } \quad 30(17.4) & \text { 86(15.3) } & 116(15.8)\end{array}$

$\begin{array}{llll}\mathrm{SSC} & 0(0.0) & 3(0.5) & 3(0.4)\end{array}$

Others $\quad 9(5.2) \quad 33(5.9) \quad 42(5.7)$

Level of education of father

\begin{tabular}{lccc} 
Illiterate & $18(10.5)$ & $46(8.1)$ & $64(8.7)$ \\
Can sign only & $19(11.0)$ & $56(9.9)$ & $67(9.1)$ \\
Class I-V & $30(17.4)$ & $87(15.4)$ & $117(15.9)$ \\
Class VI-X & $36(20.9)$ & $155(27.5)$ & $191(26.0)$ \\
SSC & $29(16.9)$ & $120(21.3)$ & $149(20.3)$ \\
HSC & $15(8.7)$ & $54(9.5)$ & $69(9.4)$ \\
Graduate & $16(9.3)$ & $34(6.0)$ & $50(6.8)$ \\
Post-graduate & $8(4.7)$ & $17(3.0)$ & $25(3.4)$ \\
Others & $1(0.6)$ & $2(0.3)$ & $3(0.4)$ \\
Level of education of mother & & \\
Illiterate & $20(11.6)$ & $59(10.5)$ & $79(10.7)$ \\
Can sign only & $12(7.0)$ & $59(10.5)$ & $71(9.7)$ \\
Class I-V & $41(23.8)$ & $88(15.6)$ & $129(17.6)$ \\
Class VI-X & $54(31.4)$ & $207(36.8)$ & $261(35.5)$ \\
SSC & $22(12.8)$ & $83(14.7)$ & $105(14.3)$ \\
HSC & $12(7.0)$ & $41(7.3)$ & $53(7.2)$ \\
Graduate & $7(4.1)$ & $15(2.6)$ & $22(3.0)$ \\
Post-graduate & $4(2.3)$ & $11(2.0)$ & $15(2.0)$ \\
\hline
\end{tabular}


Table I

Socio-demographic characteristics of the children

\section{Occupation of father}

Business

Service holder

$80(46.5)$

37(21.5)

$18(10.5)$

Farming

$37(21.5)$

$151(87.8)$

$12(7.0)$

$3(1.7)$

$6(3.5)$

Others

\section{Type of family}

Nuclear

113(65.7)

Joint

Number of family members

5 or less

112(65.1)

6-10

50(29.1)

$10(5.8)$

11 and above

Monthly family income

Tk.10,000 or less

Tk.10,001-Tk.30,000

Tk.30,001 or more

\section{Housing}

Kacha

36(20.9)

24(14.0)

Pucca

112(65.1)

Semi-pucca

Source of drinking water

Tube well

Well

156(90.7)

$0(0.0)$

Others (motor pumps)

Type of sanitation

Sanitary latrine

Non-sanitary latrine

70(40.7)

154(89.5)
285(50.6)

119(21.1)

70(12.4)

$89(15.8)$

$506(89.9)$

$37(6.6)$

5(0.9)

15(2.6)

365(49.7)

156(21.2)

$88(12.0)$

126(17.1)

657(89.4)

49(6.7)

$8(1.1)$

21(2.9)

454(61.8)

281(38.2)

222(39.4)

369(65.5)

481(65.4)

162(28.8)

212(28.8)

32(5.7)

42(5.7)

208(36.9)

278(37.8)

297(52.8)

381(51.8)

$58(10.3)$

$76(10.3)$

155(21.1)

119(21.1)

131(17.8)

$107(19.0)$

449(61.1)

$337(59.9)$

663(90.2)

$7(1.0)$

$65(8.8)$

49(8.7)

636(86.5)

482(85.6)

$99(13.5)$
The researchers also took the advantage of studying the socio-demographic condition of children who were affected by domestic accidents in the previous year separately. The data revealed the ages of the affected children were from 1 year to 15 years. Out of 172 affected children, 29.1\% children were between the age group of 7-9 years, $23.8 \%$ of the children were between the age group of 4-6 years. On the other hand, only $12.2 \%$ of the children were between the ages of 13-15 years.
Among the 172 affected children, 59.3\% were male and $40.7 \%$ female and majority (75.6\%) were Muslims, $23.8 \%$ were Hindus \& $0.6 \%$ was Christian.

Educational level of affected children showed that, 40 (23.3\%) were illiterate \& rest $132(76.7 \%)$ were literate having different levels of education. Among the literates $5.2 \%$ could only write their names and $48.8 \%, 17.4 \%, 5.2 \%$ belong to classes I to IV, classes VI to X and others respectively. 
Among the fathers of 172 affected children, 18 (10.5\%) were illiterate \& rest 154 (89.5\%) were literate having different levels of education. Among the literates, $11 \%$ could only write their names and $17.4 \%, 26.9 \%, 16.9 \%$, $8.7 \%, 9.3 \%, 4.7 \%, 0.6 \%$ studied up to classes I to IV, classes VI to X, SSC, HSC, Graduation, Post-Graduation and others respectively.

Whereas, out of 172 affected children's mothers, 20 (11.6\%) were illiterate \& rest 152 (88.4\%) were literate having different levels of education. Among the literates, $7 \%$ could only write their names and $23.8 \%, 31.4 \%, 12.8 \%, 7 \%, 4.1 \%$, $2.3 \%$ studied up to classes I to IV, classes VI to X, SSC, HSC, Graduation, Post-Graduation respectively.

Most of the affected children's fathers, i.e. 80 (46.5\%) were businessmen. Rest of the fathers were service holders (21.5\%), farmers $(10.5 \%)$ or in other professions $(21.5 \%)$. While most i.e. 151 (87.8\%) of mothers of affected children were housewives. Rest of the mothers were service holders $(7 \%)$, businesswomen $(1.7 \%)$ or in other professions $(3.5 \%)$.

The study also showed that out of 172 affected children, most $(65.7 \%)$ of the children belonged to nuclear families and rest (34.3\%) belonged to joint families.

The family members of the affected children of this study ranged from 3 to 23 in number. The mean number of family members was $5.80( \pm 3.26)$. Among 172 affected children, $65.1 \%$ had 5 or less family members, $29.1 \%$ had 6 to 10 family members, $5.8 \%$ had 11 or more family members.

The monthly family income of the affected children ranged from taka 1000 to 90,000 . Mean family income was 17125 ( $\pm 13,303.60)$ taka. Out of 172 affected children's families, only 18 families (10.5\%) were in the group of taka 30,001 or above. 70 (40.7\%) of the families were below the income group of taka 10,000 or less and 84 (48.8\%) of the families have the monthly family income of taka 10,001-30,000.

The study also revealed that out of 172 affected children $20.9 \%$ dwell in kacha house, $65.1 \%$ live in semi-pucca house, $14 \%$ live in pucca house. Majority of the affected children i.e. $156(90.7 \%)$ drink water from tube-well and rest $16(9.3 \%)$ drink water from other source, i.e. motor pumps. The alarming thing was that $18(10.5 \%)$ still use non-sanitary latrine (Table-I).

The study revealed that out of 172 children who had experienced domestic accidentsin the previous year, most common types were injury from sharp objects and fall from heights (both 33.1\%). Injury from blunt objects were $6.4 \%$, burn injuries were $8.7 \%$, burns from hot liquids were
$7.6 \%$, drowning were $4.1 \%$, insecticide poisonings were $1.2 \%$, Kerosene poisonings were $0.6 \%$, Electrocutions were $2.9 \%$, Choking were $1.2 \%$. one child was bitten by an insect and one by a snake.

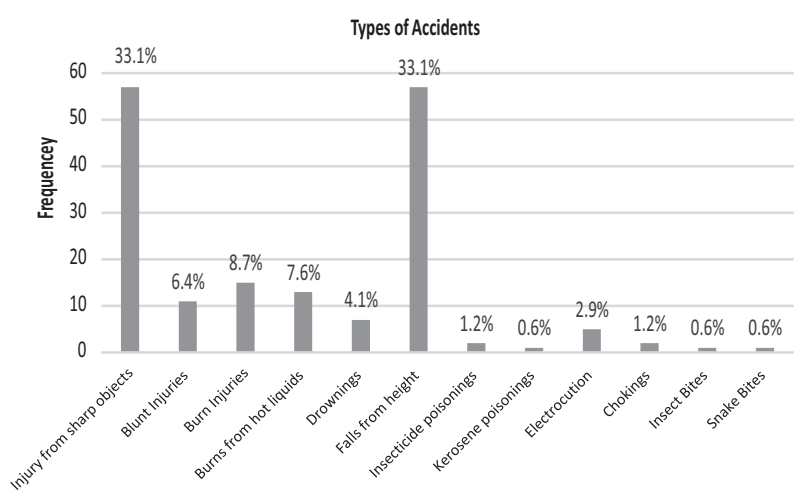

Fig.-2: Distribution of children by types of accidents

While asking about the season when accidents have occurred, it was found that $30.23 \%$ occurred in summer, $23.25 \%$ occurred in rainy season, $6.4 \%$ occurred in autumn, $6.4 \%$ in late autumn, $32.55 \%$ in winter \& $1.17 \%$ in spring (Fig.-3).

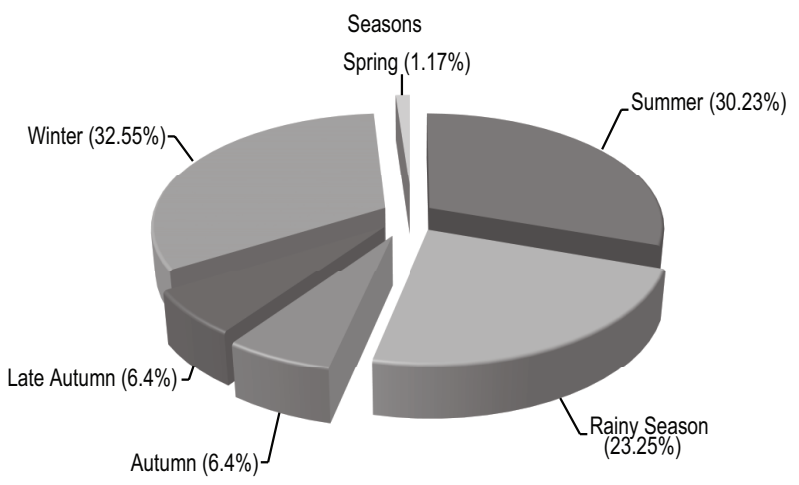

Fig.-3: Distribution of accidents by Season

Regarding the place, most $(56.4 \%)$ of the accidents occurred in the surroundings of the house and the rest (43.6\%) occurred inside the house (Fig.-4).

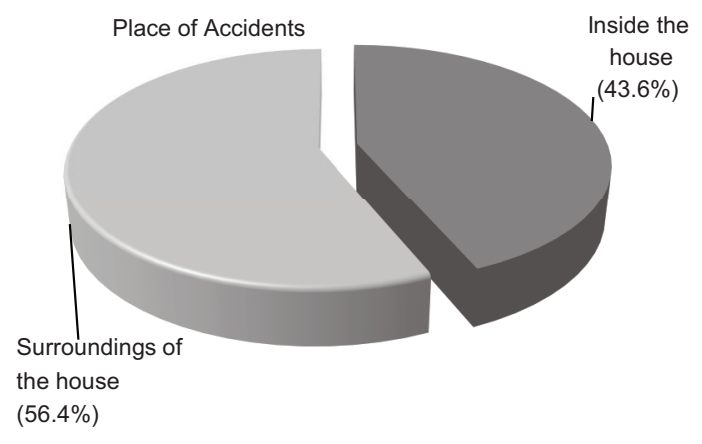

Fig.-4: Distribution of accidents by place 
In the present study only $6.98 \%$ of 172 children suffered from disabilities whereas $93.02 \%$ did not (Fig.-5).

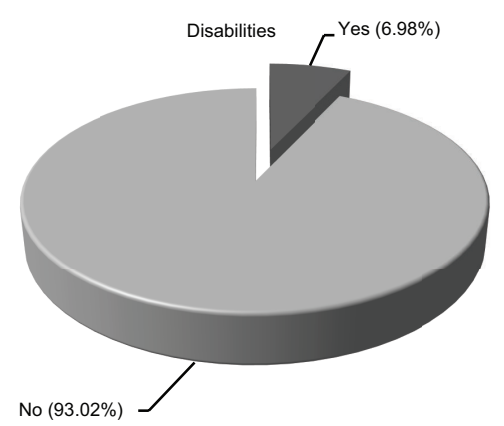

Fig.-5: Distribution of accidents according to disabilities produced by them

Out of 172 affected children $59.8 \%$ took treatment and the rest (40.2\%) did not (Fig. 6).

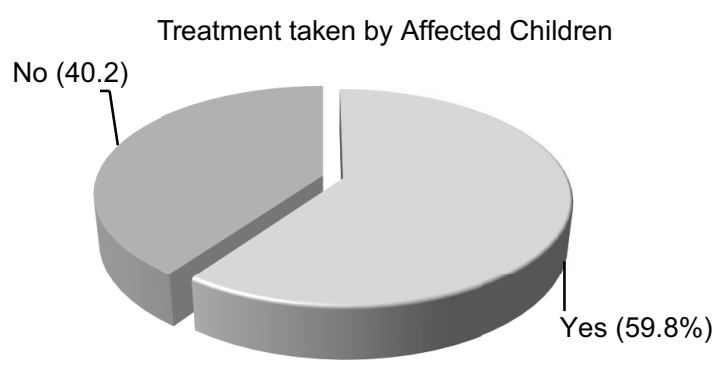

Fig. -6. Distribution of affected children by treatment taken

The study showed that preventive measures to reduce the recurrence of accidents were taken by only $7 \%$ of the affected children (Fig.-7).

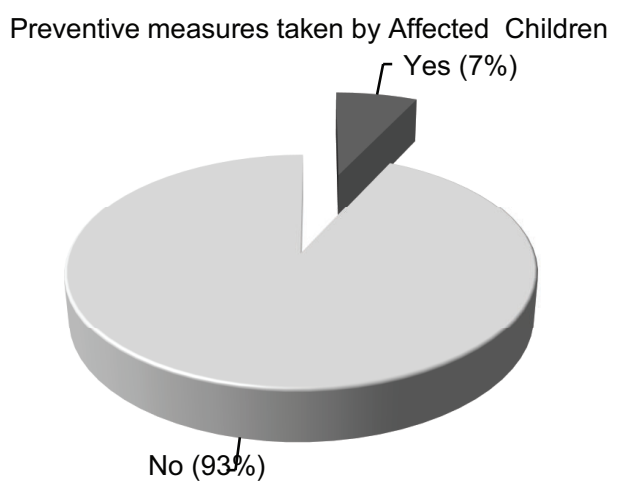

Fig.-7: Distribution of affected children by taking preventive measures
When the accidents of different types were analyzed separately, it was found thatamong the 57 affected children with injuries from sharp objects, most (40.4\%) of the cases occurred in summer. Maximum (52.6\%) incidents occurred inside the house than outside. Only $3.5 \%$ of them suffered from disabilities. Treatment was taken by the majority (77.2\%) but measures to prevent recurrence of injury were taken by only $1.8 \%$.

Among the 11 children afflicted with injuries from blunt objects, most $(45.5 \%)$ of the cases occurred in the rainy season and majority (81.8\%) incidents occurred in the surroundings of the house. Only $18.2 \%$ of them suffered from disabilities. Treatment was taken by the majority $(54.5 \%)$ but measures to prevent recurrence of injury were taken by none.

Out of 172 affected children, 15 suffered from burn injuries. Among them, most (33.3\%) of the cases occurred in winter. More $(53.3 \%)$ incidents occurred in the surroundings of the house. Only $6.7 \%$ of them suffered from disabilities. Treatment was taken by the majority $(80 \%)$ but measures to prevent recurrence of injury were taken by $6.7 \%$.

Thirteen children who suffered burns from hot liquids, most $(61.5 \%)$ of the cases occurred in winter. Majority $(92.3 \%)$ incidents occurred inside the house. None of them suffered from disabilities. Treatment was taken by the majority $(69.2 \%)$ but measures to prevent recurrence of injury were taken by only by $7.7 \%$.

In the present study, 7 children had experienced the incidence of drowning. All the cases occurred in the rainy season and in the surroundings of the house. None of them suffered from disabilities. Treatment was taken by only $14.3 \%$ but measures to prevent the recurrence were taken by $57.1 \%$ of them.

One of the common causes of accidents in the study was falls from heights. Majority (33.3\%) of the cases occurred in winter. Most (73.7\%) of the incidents occurred in the surroundings of the house. Most (87.7\%) of them did not suffer from disabilities. Treatment was taken by $63.2 \%$ but measures to prevent recurrence of injury were taken by only $5.3 \%$ (Table-II). 


\section{Table-II}

Distribution of different types of accidents by their characteristics

\begin{tabular}{|c|c|c|c|c|c|c|}
\hline \multirow[b]{2}{*}{ Type of Accident } & \multicolumn{6}{|c|}{ Frequency (Percentage) } \\
\hline & $\begin{array}{c}\text { Sharp } \\
\text { injuries }\end{array}$ & $\begin{array}{c}\text { Blunt } \\
\text { injuries }\end{array}$ & $\begin{array}{c}\text { Burn } \\
\text { injuries }\end{array}$ & $\begin{array}{c}\text { Burns from } \\
\text { hot liquid }\end{array}$ & Drowning & $\begin{array}{c}\text { Falls from } \\
\text { height }\end{array}$ \\
\hline Total & $57(100 \%)$ & $11(100 \%)$ & $15(100 \%)$ & $13(100 \%)$ & $7(100 \%)$ & $57(100 \%)$ \\
\hline \multicolumn{7}{|l|}{ Time (in Bengali season) } \\
\hline Summer & $23(40.4 \%)$ & $0(0 \%)$ & $6(40 \%)$ & $2(15.4 \%)$ & $0(0 \%)$ & $18(31.6 \%)$ \\
\hline Rainy season & $6(10.5 \%)$ & $5(45.5 \%)$ & $1(6.7 \%)$ & $2(15.4 \%)$ & $7(100 \%)$ & $13(22.8 \%)$ \\
\hline Autumn & $5(8.8 \%)$ & $1(9.1 \%)$ & $2(13.3 \%)$ & $0(0 \%)$ & $0(0 \%)$ & $3(5.3 \%)$ \\
\hline Late autumn & $3(5.3 \%)$ & $1(9.1 \%)$ & $1(6.7 \%)$ & $1(7.7 \%)$ & $0(0 \%)$ & $4(7 \%)$ \\
\hline Winter & $18(31.6 \%)$ & $4(36.4 \%)$ & $5(33.3 \%)$ & $8(61.5 \%)$ & $0(0 \%)$ & $19(33.3 \%)$ \\
\hline Spring & $2(3.5 \%)$ & $0(0 \%)$ & $0(0 \%)$ & $0(0 \%)$ & $0(0 \%)$ & $0(0 \%)$ \\
\hline \multicolumn{7}{|l|}{ Place } \\
\hline Inside the house & $30(52.6 \%)$ & $2(18.2 \%)$ & $7(46.7 \%)$ & $12(92.3 \%)$ & $0(0 \%)$ & $15(26.3 \%)$ \\
\hline In the surroundings of the house & $27(47.4 \%)$ & $9(81.8 \%)$ & $8(53.3 \%)$ & $1(7.7 \%)$ & $7(100 \%)$ & $42(73.7 \%)$ \\
\hline \multicolumn{7}{|l|}{ Any disability caused } \\
\hline Yes & $2(3.5 \%)$ & $2(18.2 \%)$ & $1(6.7 \%)$ & $0(0 \%)$ & $0(0 \%)$ & $7(12.3 \%)$ \\
\hline No & $55(96.5 \%)$ & $9(81.8 \%)$ & $14(93.3 \%)$ & $13(100 \%)$ & $7(100 \%)$ & $50(87.7 \%)$ \\
\hline \multicolumn{7}{|l|}{ Treatment } \\
\hline Yes & $44(7.2 \%)$ & $6(54.5 \%)$ & $12(80 \%)$ & $9(69.2 \%)$ & $1(14.3 \%)$ & $36(63.2 \%)$ \\
\hline No & $13(22.8 \%)$ & $5(54.5 \%)$ & $3(20 \%)$ & $4(30.8 \%)$ & $6(85.7 \%)$ & $21(36.8 \%)$ \\
\hline \multicolumn{7}{|l|}{ Type of treatment } \\
\hline Medicine & $23(40.4 \%)$ & $4(36.4 \%)$ & $4(26.7 \%)$ & $2(15.4 \%)$ & $1(14.3 \%)$ & $23(40.4 \%)$ \\
\hline Topical use of medicine & $21(36.8 \%)$ & $2(18.2 \%)$ & $8(73.3 \%)$ & $7(53.8 \%)$ & $0(0 \%)$ & $13(22.8 \%)$ \\
\hline \multicolumn{7}{|c|}{ Measures taken to prevent recurrence of injury } \\
\hline Yes & $1(1.8 \%)$ & $0(0 \%)$ & $1(6.7 \%)$ & $1(7.7 \%)$ & $4(57.1 \%)$ & $3(5.3 \%)$ \\
\hline No & $56(98.2 \%)$ & $11(100 \%)$ & $14(93.3 \%)$ & $12(92.3 \%)$ & $3(42.9 \%)$ & $54(94.7 \%)$ \\
\hline
\end{tabular}

\section{Discussion}

The present cross sectional type of descriptive study was conducted with a view to determine the proportion of domestic accidents among the under 15 children of rural areas of Bangladesh. Parents of seven hundred thirty-five under 15 children of Kaliakair Upazilla under the district of Gazipur were interviewed with an interviewer administered semi-structured questionnaire.

Among the 735 children in the study, only 172 (23.4\%) had suffered from domestic accidents in the previous one year and $563(76.65 \%)$ had not. This finding is not consistent with another study carried out from October 2010 to May 2011 in the same region where the proportion of domestic accidents was $58.3 \% .{ }^{10}$ The study showed that injury from sharp objects (33.1\%) and falling from heights (33.1\%) are the predominant causes of the domestic accidents. This is consistent with findings of other studies. ${ }^{10-14}$ The next proportion of accidents $(8.7 \%)$ are due to burns while $7.6 \%$ are by burns from hot liquids. Kerosene poisoning (0.6\%), insect bites $(0.6 \%)$ and snakebites $(0.6 \%)$ have the lowest incidence.

Out of 172 children, majority (32.55\%) of the accidents occurred in winter; $30.23 \%$ occurred in summer, $23.25 \%$ occurred in the rainy season, $6.4 \%$ occurred in autumn, $6.4 \%$ in late autumn and $1.17 \%$ in spring. This is in contrast with another study where majority of the accidents had occurred in summer. ${ }^{10}$ During the study, it was found that accidents of most (56.4\%) of the children occurred in the surroundings of the house and the rest (43.6\%) occurred inside the house. This is in contrast to another study 
where the commonest place of accident was inside the house $(58.69 \%) .{ }^{10}$ The findings reveal that only $6.98 \%$ of 172 children suffered from disabilities whereas $93.02 \%$ did not. This finding is quite similar to another study where only $9.68 \%$ developed disabilities due to the accidents. ${ }^{22}$ Among 172 affected children, 59.8\% took treatment and the rest $(40.2 \%)$ did not and in only $7 \%$ cases preventive measures were taken to prevent recurrence of diseases.

The mean age of the children in this study was 7.05 ( \pm 3.842 ) years. The maximum portion $(27.9 \%)$ of the children belongs to the age group of 4-6 years. Whereas the mean age of the affected children was 7.66 $( \pm 3.583)$ years. Among them, the majority (29.1\%) were in the age group of 7-9 years.

Among the 735 children, 53.7\% were males and 46.3\% females whereas $59.3 \%$ were males and $40.7 \%$ were females in the affected children. This is quite close to findings from other studies of domestic accidents, where $56 \%$ males and $44 \%$ females $^{15}$, and $52.6 \%$ males and $47.4 \%$ females were affected. ${ }^{9}$ It indicates that males are more at risk of being affected by domestic accidents than females.

In this study most $(81.6 \%)$ of the children were Muslims reflecting the population pattern of Bangladesh.

The education levels of the children of this study revealed that most $(70.6 \%)$ children were literate having different levels of education. The study revealed that most (49.7\%) of the children's fathers were businessmen and most $(89.4 \%)$ of the children's mothers were housewives.

Most (61.8\%) of the children belonged to nuclear families. More than $65 \%$ of the children of this study as well as children inflicted with injury belonged to 1 to 5 member families. It indicates that, the concept of joint (non-nuclear) family has changed.

From the present study it was found that, majority of the respondents as well as families of affected children had monthly family income between taka 10,001 to taka 30,000.

The study showed that $21.1 \%$ of total 735 children dwelt in kancha house, $61.1 \%$ in semi-pucca house and $17.8 \%$ in pucca house whereas $20.9 \%$ of the 172 affected children dwelt in kacha house, $65.1 \%$ lived in semi-pucca house, $14 \%$ lived in pucca house. It indicates low socio-economic conditions of the rural people.

From this study we came to know that source of drinking water for affected children as well as total respondents were tube wells in more than $90 \%$ cases.

A major concern was that $13.5 \%$ of total 735 respondents and $18(10.5 \%)$ of 172 affected children still use non- sanitary latrine. Considering the fact that the Gazipur district is close to the capital city, this figure is higher than that was expected.

\section{Conclusion}

From this study it can be concluded that, out of 735 children, about a quarter were affected by domestic accidents while $76.6 \%$ were not. Injuries from sharp objects and falls from heights were equal (33.1\% each) and were the leading causes of domestic accidents. The next proportion of accidents $(8.7 \%)$ was due to burns while $7.6 \%$ were burns from hot liquids. Most (29.1\%) of the affected children were between the age group of 7-9 years and males were mostly (59.3\%) affected. The education level of most (48.8\%) of the affected children ranged from classes I-V. Most of the children in the study and the affected children belonged to nuclear families $(61.8 \%$ \& $65.7 \%$ respectively). The mean monthly family income of the respondents was $17260.82( \pm 12726.70)$ taka and that of the affected group was $17125( \pm 13303.60)$ taka. Children living in semi pucca house suffered from domestic accidents more $(65.1 \%)$ than children living in other housing. Most $(56.4 \%)$ of the accidents occurred in the surroundings of the house and the rest (43.6\%) occurred inside the house. Majority (32.55\%)of the accidents took place in winter, whereas $30.23 \%$ in summer, $23.25 \%$ in the rainy season, $6.4 \%$ in autumn, $6.4 \%$ in late autumn, $\& 1.17 \%$ in spring. It was found that only $6.98 \%$ of 172 children suffered from disabilities. Out of 172 affected children, $59.8 \%$ took treatment and the rest $(40.2 \%)$ did not. But preventive measures to prevent recurrence of accidents were taken by only $7 \%$ parents of the affected children.

In the perspective of the present study findings, further in depth and large-scale study is essential in our country to find out the nature of the domestic accidents the rural population and to create awareness about importance of preventive measures among the parents.

\section{References}

1. Wikipedia - the free encyclopedia.

2. K. Park- Park's textbook of preventive and social medicine.

3. UNICEF, Bangladesh health and injury survey report on children, 2005.

4. Leitch KM. Domestic accidents: their cause and prevention. Journal of the Royal College of General Practitioners 1978; 28: $38-45$.

5. Humanitarian news \& analysis: IRIN International (a service UN office for the coordination of humanitarian affairs).

6. Mushriqy SR, Rahman F, Svanstorm L, Khan TF. Burn mortality in Bangladesh, finding of national health injury survey.

7. Epidemiology of childhood electrocution in Bangladesh. 
8. KM Rashid, M Rahman, S Hyder- Rashid, Kabir, Hyder's textbook of community medicine and public health.

9. Rahman S, Hossain FB, Rahman M, Ima SZ. Domestic accidents in a rural community of Bangladesh: a cross sectional study on their incidence and characteristics. International institute for science, technology and education (IISTE) journal, 2012.

10. Nature of domestic accidents among the people of a selected rural area. Department of community medicine, ShaheedSuhrawardy Medical College. July 2011.

11. Nwamoh UN, Ukegbu AU. Knowledge and practices of mothers on Domestic childhood accidents in Umuahia North Local Government Area, Abia state. Pioneer medical journal, Umuahia, 2011.

12. Aruglos OS, Ikolo O, Oluwasanu M. knowledge and practices relating to domestic accidents among mothers of pre-school children in Ibadan South West local government area, Nigeria. IOSR journal of dental and medical services 2013.

13. A study of occurrence of domestic accidents in a semi-urban community. Urban health training centre, Petlad 2005.

14. Coniglio MA. Domestic Injuries in Childhood. Results of A Survey Carried Out in A Sicilian Area. European Journal of Pediatrics, October 2007.
15. Alwash R, McCarthy M. Measuring severity of injuries to children from home accidents. Archives of disease in childhood 1998; 63:635-638.

16. Sudhir, Krishna D, Channabasappa AN, Dhar M. Prevalence of domestic accidents in rural India: a cross sectional study. Scholars' journal of applied medical sciences, 2014.

17. Armstrong DB, Cole WG. Persistent hazards in the home accident pattern. American journal of public health 1949.

18. Chaudhuri VP, Shrivastava RK, Mitra M, Desai VK. Risk of domestic accidents among under five children. The Internet Journal of Family Practice, 2009; 7(1):1-11.

19. Nature of domestic accidents among the people of a selected rural area. Department of community medicine, ShaheedSuhrawardy Medical College. July 2011.

20. Ozturk C, Yildirim H, Bektas M, Elcigil A. home accidents and mothers' measurements in pre-school children. Anatolian journal of clinical investigation 2010.

21. Mashrekyab SR, Rahman A, Chowdhury SM, Giasuddin S, Svasstromb L, Linnae M. epidemiology of childhood burn: yield of largest community based injury survey in Bangladesh. Journal of international society for burn injuries 2008 . 